\title{
World Medical Association updates ethical code for physicians
}

Cite as: CMAJ 2017 November 6;189:E1372. doi: 10.1503/cmaj.109-5513

Posted on cmajnews.com on Oct. 17, 2017.

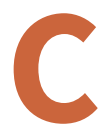

alls to respect patients, colleagues, medical instructors and students form part of the "global ethical code for all physicians" approved by the World Medical Association (WMA) at its annual general assembly, held recently in Chicago. Called "The Physician's Pledge," the document is an amended version of the Declaration of Geneva, originally adopted in 1948.

For the first time, the text states explicitly that physicians are to respect the "autonomy and dignity" of patients. The pledge also calls for doctors to keep patient information confidential, even after their deaths, and to share medical knowledge to advance health care and benefit patients.

Respect within the profession is also of utmost importance, according to the pledge. It states that every doctor is to give medical students, professors of medicine and fellow physicians "the respect and gratitude that is their due." Doctors should also attend to their own health and well-being, states the pledge.

"We hope that the declaration approved today will be used by physicians around the world to strengthen the profession's determination to maintain the highest standard of health care for patients," stated WMA president Dr. Yoshitake Yokokura.

The WMA also released a statement on bullying and harassment within the medical profession. Bullying is widespread across all specialties in medicine, in part due to the profession's hierarchical nature and the power imbalance between senior and junior physicians, according to the WMA. The many negative effects of bullying in health care - "an entirely unprofessional and destructive behaviour" that "should not be tolerated" - include anxiety, depression and absenteeism. The statement calls

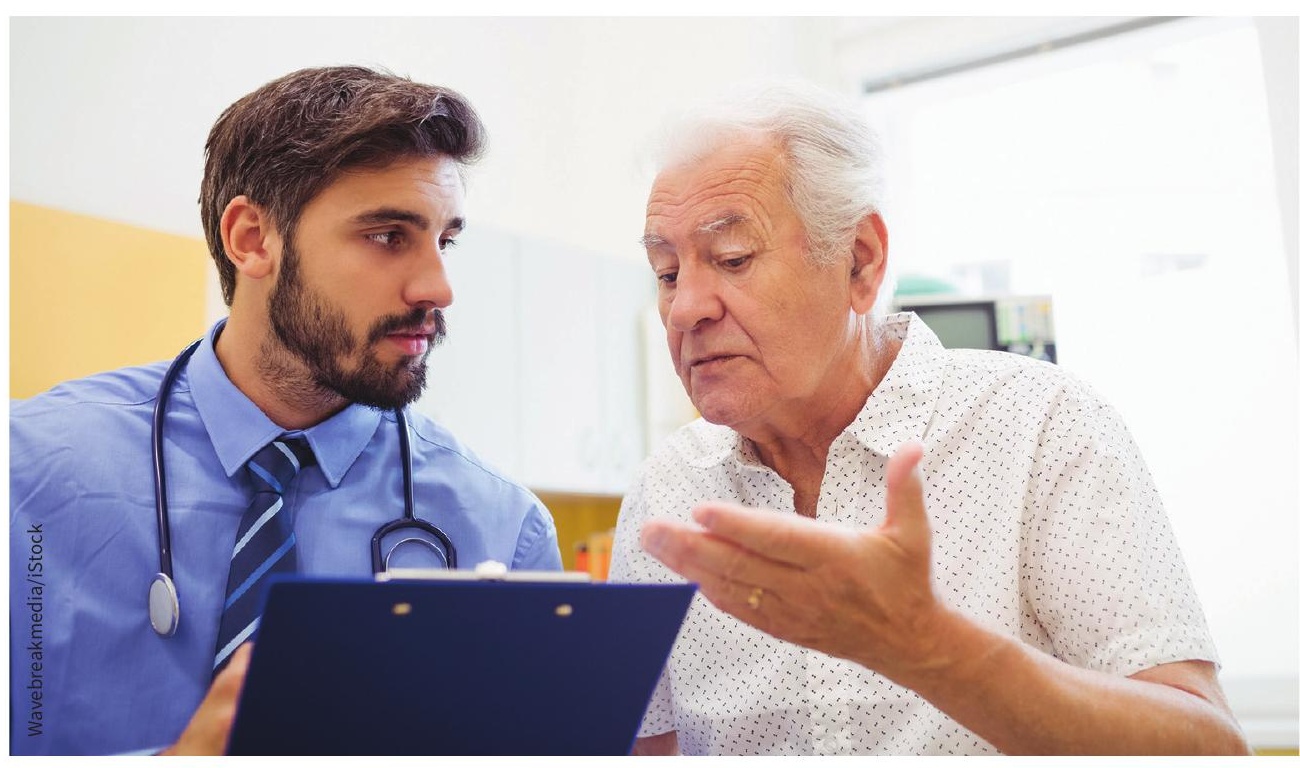

Doctors must respect a patient's autonomy, states an updated global ethical code for physicians.

upon the medical profession to take whatever steps are necessary to prevent, confront, report and eliminate bullying.

Beyond ethics and professionalism, subjects discussed at the WMA's general assembly included child abuse and neglect, improving access to health services, and the duties of physicians in times of armed conflict. Of note to Canadians, the association also came out strongly against the legalization of recreational marijuana, suggesting the drug increases risks of psychosis, especially among young people.

In particular, the WMA warned of the "ominously growing availability of cannabis or its forms in foodstuffs such as sweets and concentrates, which have enormous appeal to children and adolescents." Other potential harms noted include negative impacts on learning, memory and attention. Physicians should also be wary of the use of marijuana for medical purposes, stated the WMA, citing a lack of high-quality research in the area.
"National medical associations should support strategies to prevent and reduce the use of recreational cannabis," stated Yokokura. "It is also important that effective control measures are put in place to prevent illicit use of medical cannabis."

The burden of disease and injury associated with alcohol also remains a "critical challenge to global public health," the WMA suggested in its "Declaration on Alcohol". Excessive consumption of alcohol has been linked to more than 200 types of disease and injury, and is associated with 3.3 million deaths per year, according to the WMA. The association's recommendations on how to reduce the harms caused by alcohol include setting alcohol prices at levels that will reduce consumption, limiting the days and hours when it can be purchased, and restricting alcohol marketing.

\section{Roger Collier, CMAJ}

